\title{
ESTUDO DO COMPORTAMENTO TÉRMICO DE MATERIAIS À BASE DE BUCHA VEGETAL E ÓXIDO DE ZINCO HIDRATADO PARA APLICAÇÃO COMO REFORÇOS EM COMPÓSITOS
}

\author{
N. A. DIAS ${ }^{1}$, E. P. SANTOS $^{2}$ e M. L. C. P. da SILVA ${ }^{1}$ \\ ${ }^{1}$ Universidade de São Paulo, Departamento de Engenharia Química \\ ${ }^{2}$ Instituto Nacional de Pesquisas Espaciais, Laboratório Associado de Sensores e Materiais \\ E-mail para contato: natydias@alunos.eel.usp.br
}

\begin{abstract}
RESUMO - Os híbridos orgânico-inorgânico apresentam-se como uma alternativa na produção de novos materiais multifuncionais, nos quais as estabilidades térmica e química das cerâmicas aliada à flexibilidade e processabilidade de polímeros ou fibras naturais proporcionam propriedades sinérgicas devido às interações entre as fases. Tal efeito sinérgico tem se mostrado eficiente como reforço em compósitos poliméricos com a adição da fase inorgânica sob a forma de óxido metálico hidratado. Este trabalho visa a preparação de híbridos orgânicoinorgânico como novos materiais de reforço, combinando a bucha tratada (BT) e o óxido de zinco hidratado. Previamente, a bucha foi tratada quimicamente e na sequência os híbridos $\left(\mathrm{BT} / \mathrm{ZnO} \cdot \mathrm{nH}_{2} \mathrm{O}\right)$ foram sintetizados em diferentes proporções (98/2 a 94/6). Em seguida, avaliou-se o comportamento térmico dos híbridos por TGA/DTG. De acordo com os resultados, definiu-se a proporção 98BT/2ZnO. $\mathrm{nH}_{2} \mathrm{O}$ como a de melhor incorporação do óxido hidratado na celulose.
\end{abstract}

\section{INTRODUÇÃO}

A combinação entre diferentes materiais com propriedades distintas é considerada como quesito para a produção de um novo produto com características intrínsecas. Os híbridos orgânico-inorgânico são uma alternativa para o desenvolvimento de novos materiais multifuncionais em várias aplicações.

Os híbridos orgânico-inorgânico apresentam propriedades térmicas, ópticas e mecânicas, aliadas à estabilidade térmica e química de materiais cerâmicos com a flexibilidade e processabilidade de componentes orgânicos, tais como polímeros e fibras vegetais. Estes materiais podem ser obtidos por três maneiras distintas: incorporação física dos constituintes; ligações químicas entre os componentes e pela combinação de ambos os métodos (JOSÉ; PRADO, 2005). Destaca-se o segundo método, pela ocorrência de ligações covalentes entre a fração orgânica e inorgânica, onde a combinação entre os componentes apresenta-se bastante satisfatória como reforço em compósitos poliméricos, na qual os óxidos metálicos hidratados constituem a fase inorgânica (MULINARI et al., 2009; MULINARI et al., 2010). Dos óxidos mais comumente utilizados podem ser citados o óxido de alumínio hidratado, $\mathrm{Al}_{2} \mathrm{O}_{3} \cdot \mathrm{nH}_{2} \mathrm{O}$ (SILVA, 2013); o óxido de zircônio hidratado, $\mathrm{ZrO}_{\mathrm{nH}} \mathrm{O}$ (MULINARI et al., 2009; MULINARI et al., 2010), o óxido de nióbio hidratado, 
$\mathrm{Nb}_{2} \mathrm{O}_{5} \cdot \mathrm{nH}_{2} \mathrm{O}$ (OTTOBONI, 2011; MASCHIO et al., 2012) e o óxido de zinco hidratado, $\mathrm{ZnO} . \mathrm{nH}_{2} \mathrm{O}$ (SANTOS et al., 2013), dentre outros. Além disso, deve-se salientar que estes materiais não exibem somente uma mera soma de características de seus precursores, e sim um sinergismo devido à interação de ambas as fases, enquanto novas propriedades são obtidas (CUNHA et al., 2010).

Neste contexto, este trabalho tem como objetivo desenvolver híbridos orgânicoinorgânico, a partir da bucha vegetal e do óxido de zinco hidratado, como novos materiais de reforço e avaliar seu comportamento térmico.

\section{MATERIAIS E MÉTODOS}

\subsection{Materiais}

As buchas vegetais (Luffa cylindrica) utilizadas nos tratamentos químicos, previamente limpas e secas, foram cortadas em rodelas de aproximadamente $1,5 \mathrm{~cm}$ de espessura. A bucha tratada empregada nas formulações dos híbridos foi obtida via ataque básico/ácido e devidamente purificada. Para o ataque básico utilizou-se uma solução de hidróxido de sódio, $\mathrm{NaOH}, 0,1 \mathrm{~mol} / \mathrm{L}$ e para o ataque ácido uma mistura ácida de ácido acético, $\mathrm{CH}_{3} \mathrm{COOH}, 80 \%$ $\mathrm{v} / \mathrm{v}$ e ácido nítrico, $\mathrm{HNO}_{3}, 65 \% \mathrm{~m} / \mathrm{m}$. Para a obtenção do óxido metálico hidratado e dos híbridos utilizou-se como material de partida o zinco metálico.

\subsection{Tratamento químico da bucha vegetal}

Para o tratamento químico da bucha vegetal foram empregados dois ataques sequenciais: um ácido e um básico, baseado em estudo previamente realizado.

Ataque ácido: para este tratamento empregou-se uma adaptação da metodologia proposta por Brendel et al. (2000). As buchas, previamente limpas e secas, foram colocadas em um béquer e adicionada uma mistura de ácidos acético/nítrico. O sistema foi mantido sob agitação a $120^{\circ} \mathrm{C}$ por $20 \mathrm{~min}$ e, após aquecimento, filtrado a vácuo e lavado com água deionizada até $\mathrm{pH}$ neutro. Em seguida, as buchas foram secas em estufa a $50{ }^{\circ} \mathrm{C}$ até peso constante.

Ataque básico: as buchas, obtidas no tratamento anterior, foram transferidas para um béquer e imersas em solução de $\mathrm{NaOH} 0,1 \mathrm{~mol} / \mathrm{L}$ e mantidas sob aquecimento, por 20 minutos, após a solução atingir a ebulição. Em seguida, foram filtradas a vácuo e lavadas com água deionizada até $\mathrm{pH}$ neutro. As buchas foram secas em estufa a $50^{\circ} \mathrm{C}$ até peso constante.

\subsection{Síntese do óxido metálico hidratado}

$\mathrm{O}$ óxido de zinco hidratado, $\mathrm{ZnO} \cdot \mathrm{nH}_{2} \mathrm{O}$, foi sintetizado via precipitação convencional (PC), segundo metodologia apresentada por Rodrigues e Silva (2009). Inicialmente, zinco metálico foi dissolvido em $\mathrm{HCl}(36,5 \% \mathrm{~m} / \mathrm{m})$ e precipitado lentamente com solução de $\mathrm{NH}_{4} \mathrm{OH}$ (1:3), sob constante agitação, até $\mathrm{pH}=10$. O precipitado foi filtrado a vácuo e lavado com água deionizada até completa remoção de íons cloreto $\left(\mathrm{Cl}^{-}\right)$, efetuando-se testes com solução de $\mathrm{AgNO}_{3} 0,05 \mathrm{~mol} / \mathrm{L}$ nas águas de lavagem. O precipitado foi seco em estufa a 50 
${ }^{\circ} \mathrm{C}$ até peso constante.

\subsection{Síntese dos híbridos orgânico-inorgânico}

Os híbridos foram sintetizados pelo método PC, como descrito no item 2.3, porém com a adição da bucha tratada previamente intumescida por $1 \mathrm{~h}$ em água. $\mathrm{O}$ material obtido foi seco em estufa a $50{ }^{\circ} \mathrm{C}$ até peso constante. Repetiu-se o mesmo procedimento com variações de massas nas seguintes proporções: 98BT/2ZnO. $\mathrm{nH}_{2} \mathrm{O}, 97 \mathrm{BT} / 3 \mathrm{ZnO} . \mathrm{nH}_{2} \mathrm{O}, 96 \mathrm{BT}$ /4ZnO. $\mathrm{nH}_{2} \mathrm{O}, 95 \mathrm{BT} / 5 \mathrm{ZnO} . \mathrm{nH}_{2} \mathrm{O}$ e $94 \mathrm{BT} / 6 \mathrm{ZnO} \mathrm{nH}_{2} \mathrm{O}$.

\subsection{Caracterização}

O comportamento térmico de todos os materiais foi avaliado por TGA, em uma termobalança Shimadzu, modelo TGA-50, sob atmosfera de nitrogênio, com vazão de 50 $\mathrm{mL} / \mathrm{min}$ e taxa de aquecimento de $20^{\circ} \mathrm{C} / \mathrm{min}$, no intervalo da temperatura ambiente até $900^{\circ} \mathrm{C}$.

\section{RESULTADOS E DISCUSSÃO}

\subsection{Termogravimetria, TGA/DTG}

A Tabela 1 apresenta os dados das curvas TGA/DTG para as buchas pura e tratada quimicamente com $\mathrm{CH}_{3} \mathrm{COOH} / \mathrm{NaOH}$, para o óxido de zinco hidratado e para os híbridos, em atmosfera de nitrogênio. 
Tabela 1 - Dados das curvas TGA/DTG das buchas pura e tratada, óxido de zinco hidratado e híbridos

\begin{tabular}{|c|c|c|c|c|c|}
\hline MATERIAL & $\begin{array}{c}\text { Intervalos } \\
\left({ }^{\circ} \mathrm{C}\right)\end{array}$ & $\begin{array}{c}\text { Perda } \\
\text { de massa } \\
(\%)\end{array}$ & $\begin{array}{c}\text { Temp. pela } \\
\text { DTG } \\
\left({ }^{\circ} \mathrm{C}\right)\end{array}$ & $\begin{array}{c}\text { Resíduo } \\
\text { (\%) }\end{array}$ & $\begin{array}{c}\text { Resíduo } \\
\text { teórico } \\
(\%)\end{array}$ \\
\hline $\begin{array}{c}\text { BUCHA } \\
\text { PURA }\end{array}$ & $\begin{array}{c}25-170 \\
170-525 \\
525-900\end{array}$ & $\begin{array}{l}7,33 \\
67,66 \\
17,48\end{array}$ & $\begin{array}{c}72 \\
377 \\
-\end{array}$ & 7,53 & - \\
\hline $\begin{array}{c}\text { BUCHA } \\
\text { TRATADA }\end{array}$ & $\begin{array}{c}25-190 \\
190-410 \\
410-900\end{array}$ & $\begin{array}{c}2,92 \\
76,35 \\
13,72\end{array}$ & $\begin{array}{c}64 \\
361 \\
598\end{array}$ & 7,01 & - \\
\hline ZnO.nH ${ }_{2} \mathrm{O}$ & $\begin{array}{l}25-150 \\
150-900\end{array}$ & $\begin{array}{c}1,83 \\
20,37\end{array}$ & $\begin{array}{c}86 \\
273\end{array}$ & 77,8 & - \\
\hline Híbrido 98:2 & $\begin{array}{c}25-170 \\
170-450 \\
450-900\end{array}$ & $\begin{array}{c}3,91 \\
80,91 \\
9,64\end{array}$ & $\begin{array}{c}64 \\
394 \\
-\end{array}$ & 5,54 & 9,01 \\
\hline Híbrido 97:3 & $\begin{array}{c}25-165 \\
165-455 \\
455-900\end{array}$ & $\begin{array}{c}4,25 \\
82,80 \\
9,27\end{array}$ & $\begin{array}{c}62 \\
387 \\
-\end{array}$ & 3,68 & 10,01 \\
\hline Híbrido 96:4 & $\begin{array}{c}25-200 \\
200-480 \\
480-900\end{array}$ & $\begin{array}{c}5,55 \\
78,29 \\
9,84\end{array}$ & $\begin{array}{c}65 \\
390 \\
641\end{array}$ & 6,32 & 11,01 \\
\hline Híbrido 95:5 & $\begin{array}{c}25-185 \\
185-450 \\
450-900\end{array}$ & $\begin{array}{c}3,28 \\
78,25 \\
12,63\end{array}$ & $\begin{array}{c}67 \\
391 \\
626\end{array}$ & 5,84 & 12,01 \\
\hline Híbrido 94:6 & $\begin{array}{c}25-200 \\
200-470 \\
470-900\end{array}$ & $\begin{array}{c}5,10 \\
85,01 \\
5,07\end{array}$ & $\begin{array}{c}63 \\
380 \\
572\end{array}$ & 4,82 & 13,01 \\
\hline
\end{tabular}

Segundo a Tabela 1 as curvas TGA/DTG para as buchas pura e tratada apresentam três eventos térmicos distintos: desidratação, decomposição e degradação, respectivamente. Comparando os eventos de desidratação, nota-se uma redução da perda de massa para a bucha 
tratada $(2,92 \%)$ em relação à bucha pura $(7,33 \%)$. Entretanto, no segundo evento da bucha tratada, a perda de massa foi de $76,35 \%$ e na bucha pura esta perda foi de $67,66 \%$, com a diminuição na temperatura de decomposição da bucha tratada quimicamente $\left(361{ }^{\circ} \mathrm{C}\right) \mathrm{em}$ relação à bucha pura $\left(377^{\circ} \mathrm{C}\right)$. Segundo D'Almeida et al. (2006), o tratamento químico pode reduzir a quantidade de lignina e hemicelulose presente na bucha vegetal, que contribui para o isolamento da celulose, a qual é mais susceptível à decomposição térmica (MONTEIRO et al., 2012).

A curva TGA/DTG do óxido de zinco hidratado apresenta dois eventos térmicos: o primeiro, da temperatura ambiente até $150^{\circ} \mathrm{C}$, refere-se à perda de moléculas de água mais fracamente ligadas, com uma perda de massa de $1,83 \%$ e uma velocidade máxima de perda em $86{ }^{\circ} \mathrm{C}$. O segundo, no intervalo de 150 a $900^{\circ} \mathrm{C}$, refere-se à perda de moléculas de água mais fortemente ligadas, exibiu uma perda de massa de $20,37 \%$ com uma velocidade máxima de perda de $273{ }^{\circ} \mathrm{C}$ (TAGLIAFERRO et al., 2005).

A termogravimetria também possibilita o cálculo do grau de hidratação do óxido metálico $(n)$, além da identificação dos eventos térmicos e dos cálculos das perdas de massa referentes a estes eventos. Segundo Tagliaferro et al. (2005), o grau de hidratação pode ser definido de acordo com a Equação 1:

$$
18 n=X(M+18 n) / 100
$$

$\mathrm{X}=$ porcentagem de massa de água liberada;

$\mathrm{M}=$ massa molecular do óxido resultante da análise térmica;

$n=$ número de moléculas de água.

Logo, o grau de hidratação $(n)$ calculado forneceu a seguinte estequiometria para o material sintetizado: $\mathrm{ZnO} .1,3 \mathrm{H}_{2} \mathrm{O}$.

As curvas TGA/DTG dos híbridos apresentam três eventos térmicos distintos, nos quais o primeiro refere-se à desidratação da bucha tratada quimicamente e do óxido de zinco hidratado. O segundo evento denota a decomposição da bucha tratada e a segunda desidratação do óxido de zinco hidratado, referente a água mais fortemente ligada. E o terceiro evento refere-se à degradação da bucha tratada. Baseado nos resultados apresentados na Tabela 1, a interação do óxido metálico hidratado com a celulose da bucha tratada torna-se evidente devido à diferença de temperaturas da segunda perda de massa, dos materiais puros (bucha tratada e óxido metálico hidratado) em relação aos híbridos. Isto é, quanto maior esta diferença de temperatura entre o híbrido e o material puro, maior é a interação entre eles. Os resultados apresentados estão de acordo com trabalhos anteriores do grupo (TAGLIAFERRO et al., 2005; MASCHIO et al., 2012; SILVA, 2013; SANTOS et al., 2013). Neste caso, o híbrido que apresenta a maior interação é o 98BT/2 $\mathrm{ZnO} \cdot \mathrm{nH}_{2} \mathrm{O}$ com um $\Delta \mathrm{T}=33^{\circ} \mathrm{C}$.

A Figura 1 apresenta as curvas TGA das buchas pura e tratada, do óxido de zinco hidratado e de seus híbridos. Segundo a curva TGA do híbrido $98 \mathrm{BT} / 2 \mathrm{ZnO} \mathrm{nH}_{2} \mathrm{O}$ é possível observar uma perda de massa contínua no evento de degradação até $900{ }^{\circ} \mathrm{C}$. Ou seja, esta curva corrobora com o fato de que somente $2 \%$ em massa do óxido metálico hidratado 
promovem uma alta estabilidade térmica na bucha tratada, prolongando a degradação do híbrido devido à incorporação do óxido à bucha. Resultados semelhantes também foram observados em híbridos provenientes de outras fontes vegetais e outros óxidos metálicos hidratados (OTTOBONI, 2011; SILVA, 2013; SANTOS et al., 2013).

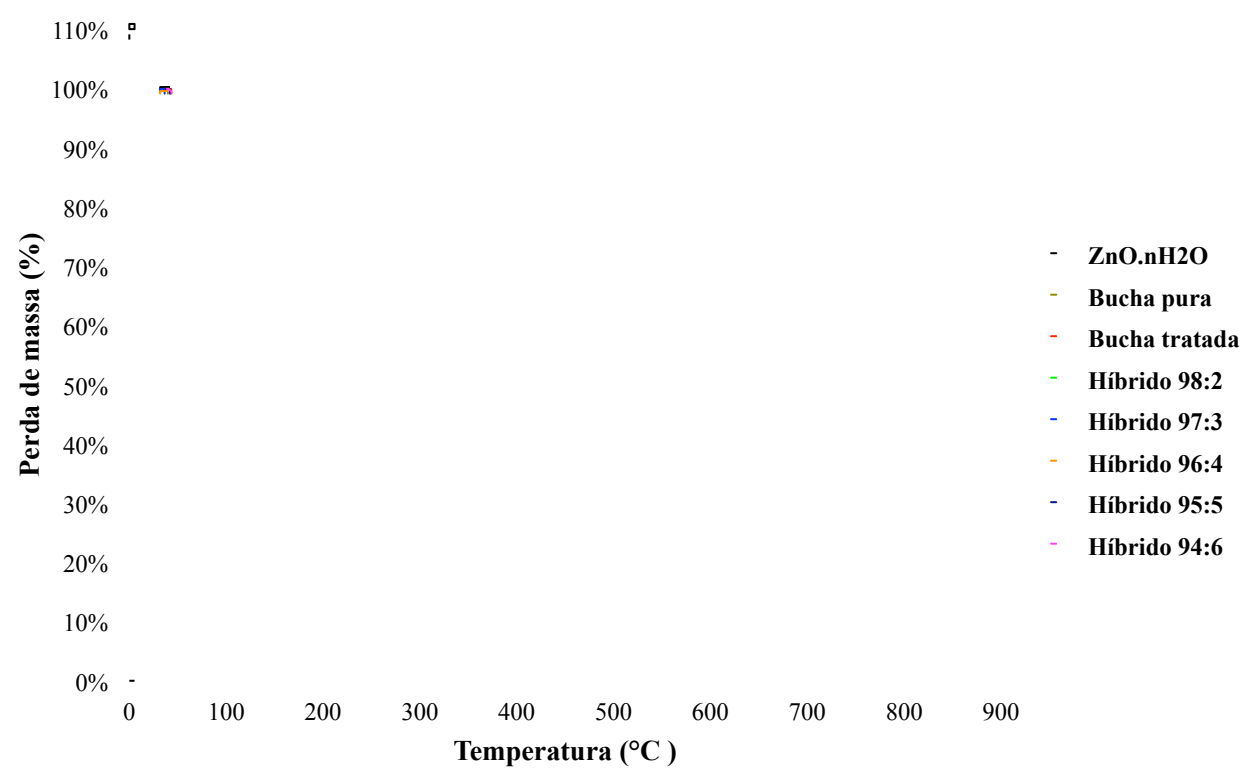

Figura 1 - Curvas TGA/DTG para as buchas pura e tratada, do óxido de zinco hidratado e seus híbridos.

Outro dado importante para a avaliação da incorporação do óxido metálico hidratado à bucha tratada é a porcentagem de resíduo, pois esta representa a quantidade de material inorgânico presente no híbrido. Segundo a Tabela 1 , o valor de resíduo mais próximo ao teórico $(9,01 \%)$ é para o híbrido 98BT/2ZnO. $\mathrm{nH}_{2} \mathrm{O}(5,54 \%)$. Esta diferença pode estar associada à própria estrutura do material (estrutura vazada), a qual fornece uma menor área de contato, dificultando a incorporação do óxido à estrutura da bucha tratada. Entretanto, apesar desta dificuldade, pode-se afirmar que houve a formação de um novo material termicamente estável, fato comprovado pelas diferenças de temperaturas já mencionadas.

Nos demais híbridos, 97BT/3ZnO.nH $\mathrm{n}_{2} \mathrm{O}, 96 \mathrm{BT} / 4 \mathrm{ZnO} \cdot \mathrm{nH}_{2} \mathrm{O}, 95 \mathrm{BT} / 5 \mathrm{ZnO} \cdot \mathrm{nH}_{2} \mathrm{O}$ e 94BT/6ZnO. $\mathrm{nH}_{2} \mathrm{O}$ o comportamento térmico foi semelhante. Apesar do híbrido 95BT/5ZnO. $\mathrm{nH}_{2} \mathrm{O}$ apresentar um $\Delta \mathrm{T}=30{ }^{\circ} \mathrm{C}$, seu valor de resíduo $(5,84 \%)$ está bem distante do valor teórico $(12,01 \%)$, desqualificando sua escolha. Isso mostra que, da quantidade estequiométrica calculada para o óxido metálico $(5 \% \mathrm{~m} / \mathrm{m})$, somente uma pequena porção foi incorporada ao material, resultando a perda de óxido por excesso, justificando assim a escolha do híbrido 98BT/2ZnO. $\mathrm{nH}_{2} \mathrm{O}$.

\section{CONCLUSÃO}

De acordo com os resultados apresentados pode-se afirmar que a incorporação do óxido de zinco hidratado à bucha tratada ocorreu em várias proporções mássicas, porém a melhor proporção do híbrido é $98 \mathrm{BT} / 2 \mathrm{ZnO} \cdot \mathrm{nH}_{2} \mathrm{O}$. Este material exibiu um aumento na temperatura 
de decomposição e prolongamento do evento de degradação, caracterizando um novo material estável termicamente.

\section{REFERÊNCIAS}

BRENDEL, O. et al. A rapid and simple method to isolate pure alpha-cellulose. Phytochem. Anal., v. 11, p. 7-10, 2000.

CUNHA, A. G.; FREIRE, C. S. R.; SILVESTRE, A. J. D., NETO, C. P. Preparation and characterization of novel highly omniphobic cellulosic fibers organic-inorganic hybrid material. Carbohydr. Polym., v. 80, p. 1048-1056, 2010.

D'ALMEIDA, A. L. F. S et al. Effects of derivatization on sponge gourd (Luffa cylindrica) fibres. Polym. Polym. Compos. v. 14, n. 1, p. 73-80, 2006.

JOSÉ, N. M.; PRADO, L. A. S. A. Materiais híbridos orgânico-inorgânicos: preparação e algumas aplicações. Quím. Nova, v. 28, n. 2, p. 281-288, 2005.

MASCHIO, L. J. et al. Preparation and characterization of cellulose/hydrous niobium oxide hybrid. Carbohydr. Polym., v. 89, p. 992-996, 2012.

MONTEIRO, S. N. et al. Thermogravimetric stability behavior of less common lignocellulosic fibers - a review. J. Mater. Res. Technol. v. 1, n. 3, p. 189-199, 2012.

MULINARI, D. R. et al. Preparation and properties of HDPE/sugarcane bagasse cellulose composites obtained for thermokinetic mixer. Carbohydr. Polym., v. 75, p. 317-321, 2009.

MULINARI, D. R. et al. Surface modification of sugarcane bagasse cellulose and its effect on mechanical and water absorption properties of sugarcane bagasse cellulose/HDPE composites. BioRes., v. 5, n. 2, p. 661-671, 2010.

OTTOBONI, F. S. Desenvolvimento de novos compósitos baseados em polietileno e híbridos gerados a partir de resíduos agrícolas modificados com óxido de nióbio. 121f. Dissertação de Mestrado, Universidade de São Paulo, São Paulo, 2011.

RODRIGUES, L. A.; SILVA, M. L. C. P. An investigation of phosphate adsorption from aqueous solution onto hydrous niobium oxide prepared by co-precipitation method. Colloids and Surfaces A: Physicochem. Eng. Aspects, v. 334, p. 191-196, 2009.

SANTOS, E. P. et al. Avaliação do comportamento térmico de híbridos orgânico- inorgânico provenientes do óxido de zinco hidratado e celulose da fibra de bananeira. In: $12^{\circ}$ Congresso Brasileiro de Polímeros, Florianópolis, 2013.

SILVA, L. P. Preparação e caracterização de híbridos de celulose do bagaço de cana-deaçúcar e óxido de alumínio hidratado para aplicação em membranas. 169f. Dissertação de Mestrado, Universidade de São Paulo, São Paulo, 2013.

TAGLIAFERRO, G. V. et al. Influência do agente precipitante na preparação do óxido de 
nióbio (V) hidratado pelo método da precipitação em solução homogênea. Quim. Nova, v. 28, n. 2, p. 250-254, 2005. 